\title{
Creating Innovation in Hospitality Industry: The Role of Brand Supporting Behavior
}

\author{
Pham Hong Liem \\ Faculty of Tourism \\ University of Khanh Hoa \\ phamhongliem@ukh.edu.vn
}

\author{
Nguyen Xuan Lan \\ Faculty of Business Administration \\ University of Da Nang \\ nguyenxuanlan@due.edu.vn
}

\begin{abstract}
Sustainable development cannot be separated from business ethics and innovation. This study proposes to test the antecedent variable for brand supporting behavior, and explore the mediating mechanism of this factor for the influence of corporate social responsibility (CSR) on employee work innovation. With 173 questionnaires collected, the hierarchical regression model is used to test the hypotheses. Discoveries have shown that CSR practices are fundamental to brand support behavior, and the important mediating role of brand supporting behavior in the influence of CSR on employee work innovation. Research results have shown the need to implement CSR in the hospitality industry, including issues of environmental protection and community support; on ensuring the interests of customers, as well as employees in the organization. Therefore, it is essential to create a community-oriented organizational climate that promotes employees' efforts in delivering on the brand promise. This is the basis for spreading the image and attractiveness of the organization's brand, and stimulating employee work innovation. Therefore, the research results are a reliable basis in making the right decisions of hotel managers, in order to create advantages as well as improve competitiveness, contributing to the recovery of the economy after the Covid-19 pandemic. The research results are also the theoretical basis for developing research models on innovation in the hospitality industry.
\end{abstract}

Index Terms-Brand supporting behavior, CSR, Employee Work Innovation, Hospitality Industry.

\section{INTRODUCTION}

$\mathrm{T}$ ODAY, the businesses want to create a competitive advantage and develop sustainably, internal businesses must be stable, including ownership of creative and innovative human resources. This is a key resource for businesses to provide products that satisfy consumers' needs. Especially in tourism service, the more customers have choices, the less they feel unsatisfied [1]. That puts pressure on businesses to provide services that satisfy customers' needs. Therefore, the organization needs members who are motivated to work actively, form positive attitudes and behaviors in the process of providing services. That is the foundation for employees to feel more excited when constantly learning skills and overcoming challenges at work.

The customers always care about the service's characteristics (uniqueness and difference). Therefore, employee work innovation in theory and practice is vital. It improves competitiveness, efficiency, quality, productivity and brand of the business [2]. In hospitality, the employees need more flexibility, creativity and skills for improving competitiveness and increasing customer's satisfaction [3]. Therefore, this is an extremely vital problem for human resources management to build a team who are brave, dynamic, competent and creative to be able to identify, understand, analyze and respond to customer needs as quickly as possible [4]. In addition, customers have the right to demand that businesses act in accordance with prevailing social values, norms and expectations. They will turn away from the company's products with no social responsibility such as: environmental destruction, tax evasion, insecurity, objectionable brand images, discriminatory messages, use of child labor. This is an important factor for the formation and spread of corporate responsibility to employees, responsibility to society, responsibility to the environment, to the community and stakeholders. That is CSR, which is considered as the foundation to help businesses develop sustainably.

There have been studies on the benefits of CSR activities for businesses as well as on the role of service staff in creating a brand image for the organization (for example, $[5,6]$ ). However, in the hospitality industry, whether CSR affects employee attitudes and behaviors has not been considered, nor is there an answer on how to get employees to act positively, and consistent with the brand promise [7]. Furthermore, research on the role of CSR in increasing employee attitudes and behaviors is a relatively new topic in Vietnam.

The expectation of this study can create practical application meanings to promote creativity and innovation of employees, thereby improving the competitiveness of the hospitality industry, and enhancing the organizational brand value. And according to the authors' research, the theoretical model of CSR, brand supporting behavior and job employee work innovation in the Vietnam hospitality industry is very few.

\section{Research Framework and Hypotheses}

\section{A. Employee work innovation}

Innovation has been defined by different authors, but all emphasize "novelty" as the core of innovation. It is a process with many stages. Scott \& Bruce (1994) define work innovation as activities such as identifying problems, thereby forming new and useful ideas or solutions. Next is the preparation of resources and implementation plan, and finally the application of ideas in practice. In terms of employees, work innovation is their active behavior in the process of forming creative ideas, developing and realizing new services, products, or methods, in order to get practical benefits [8] - [11]. Thus, through employee work innovation, businesses will accelerate the process of creating new products and services [9]. Especially in the hospitality industry, employee work innova- 
tion is the result of interactions between service staff and consumers during service delivery. In this study, the author focuses on considering the employee work innovation as multi-stage process [10].

Thus, it can be said that employee work innovation reflects their ability and problem-solving capacity. Employee work innovation has brought the organization positive consequences such as: increasing competitive advantage [10] [12], promoting cooperation among members of the organization [13]. And so, employee work innovation not only improves work efficiency but also helps them reduce stress and pressure at work. It is also a motivation to help employees improve their knowledge, professional skills, and develop themselves [13].

\section{B. Brand supporting behavior, and the relationship with employee work innovation}

Brands are formed through the organization's service delivery and assurance process. In which, the conveying of the brand, through the brand supporting behavior, is the most important [14]. In the process of conveying the brand identity into the customer's mind, the attitude and behavior of employees is a key determinant. According to Burmann and Zeplin (2005), brand supporting behavior is "an aggregate construct which describes a number of generic employee behaviors that enhance the brand identity" [15, p. 282].

In the process of providing services, service staff are considered as a bridge to provide information to customers. And they are seen by customers as brand transmitters or brand ambassadors. Therefore, besides understanding the brand stands for, service staff need to take action to protect and develop the brand. Including actions that build brands as well as deliver on brand promises. In other words, it's brand supporting behavior $[16,17]$.

In the hospitality industry, brand supporting behavior is indispensable because it is the basis for customers to evaluate the service quality of accommodation, helping to spread the brand image in the community and increasing brand value [18]. And so, brand supporting behavior has a positive effect on the organizational brand, and is the foundation for improving the work efficiency of employees [19, 20]. Therefore, the first hypothesis is proposed:

H1: Brand supporting behavior directly and positively affects employee work innovation.

\section{CSR and the relationship with brand supporting behavior}

CSR is a relatively new topic in hotel management research, and is also relatively under-reviewed in this field [21]. In the tourism business, Inoue and Lee (2011) said that CSR is reflected in the following activities: Employee relations, customer relations, community relations, environmental policy, diversity in recruitment, use of human resources, and in cooperation with suppliers [22].

According to ISO 26000:2010, CSR is an organization's responsibility to society and the environment through transparent and ethical behavior [23]. Thereby contributing to sustainable development, including health and social welfare; Pay attention to the expectations and expectations of stakeholders; Comply with applicable laws and in accordance with international standards of conduct; and is maintained throughout the organization. ISO 26000:2010 also provides guidance on seven key topics: organizational governance; human rights; labor policy; equal; consumer issues; community participation and development, and the environment.

When CSR is seen as representing the values and norms of the enterprise, it will increase the employee psychological confidence about the organization [24], will create supportive attitudes and behaviors of employees, helping to achieve the goals of the enterprise $[25,26]$. Research on organizational behavior has also demonstrated that employees not only react to the way the organization treats them, but also to the way the organization treats third parties [27].

In the tourism business, CSR is recognized as a factor creating profitability (short-term and long-term) for tourism businesses [22], so it is difficult to imagine an international company without CSR policies [28]. Moreover, organizational CSR creates a better working and organizational climate for employees. Thereby forming a positive attitude, voluntary spirit as well as their efforts to successfully exceed the expectations of the organization [29]. On that basis, the next hypothesis is proposed:

H2: CSR directly and positively affects brand supporting behavior.

\section{Brand supporting behavior play a mediating role}

Park's (2020) research also shows that when employees perceive CSR, they will put more effort in their work, will be proud of their work, and will have work engagement, thereby forming innovative behavior [30]. According to the work characteristics theory of Oldham and Hackman (2010), these perceptions are considered as positive psychological states, so it positively affects the employee's work efficiency [31].

When firms implement CSR, it shows their respect for the sustainability of the community, creating a quality relationship of trust between members of the organization, which later translates into innovation. Furthermore, the Social exchange theory has suggested that, when employees perceive the organizations initiated the voluntary social exchange nature actions for their employees, then they respond, including efforts to complete work, and actions for the reputation of the organization [32]. In other words, it is about raising employees' awareness of their role and responsibility for the success of the organization's brand and their efforts to deliver on the brand promise.

And so, brand supporting behavior is the mediator in the relationship between CSR and innovation. From the above theoretical basis, the third hypothesis is proposed:

H3: Brand supporting behavior mediates the relationship between CSR and employee work innovation.

Based on theoretical foundations, a theoretical research model is proposed and presented in Figure 1.

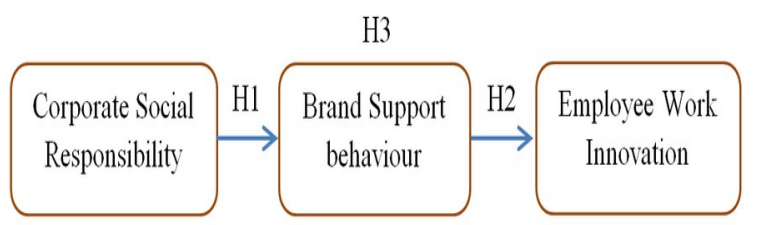

Fig. 1: Theoretical research model 


\section{Research Methodology}

The design of the study is considered as the causality category test. The research has two steps, including: preliminary (qualitative) and formal (quantitative) studies. Firstly, the author has looked for relevant documents. After that, according to experts' advice in Khanh Hoa province, we designed the appropriate questionnaires with calibrated scales. Experts are directors or deputy directors of hotels (resorts), and also lecturers of tourism training institutions.

This study uses questionnaires to collect data, test the hypothesis as well as evaluate the theoretical research model. The first is a quantitative preliminary study conducted with 30 questionnaires. The results show a good fit between the content and the concepts. Then came the formal study, with 173 questionnaires. The sample is convenience, collected from January to February, 2021.

In quantitative research, it is appropriate to inherit previously tested scales. Scales brand supporting behavior and employee work innovation are unidirectional scales. Specifically, the brand support behavior scale is inherited from Punjaisri et al. (2009), including four items related to meeting brand standards, supporting brand development, fulfilling brand promises, handling customers' requests [6]. The six items of the employee work innovation scale are inherited from Scott and Bruce (1994), such as, searches out new ideas, generates ideas, promotes and champions ideas, implementation of new ideas, innovation [10]. The CSR scale is a multi-pronged scale with eighteen items showing the organization's responsibility to (i) employees, including training and development, working environment, fairness, and personal interests $[33,34,35]$, (ii) customers, including information about products and product quality, and respect for customers $[35,36,37]$, (iii) community, including respecting the community's values, improving the quality of life, and charitable activities [33, 34, 35, 37, 38], (iv) environment, including environmental protection, energy saving, and minimizing negative impacts on the environment [35]. The items are rated on a five-point Likert scale. The software SPSS 18.0 was used for supporting.

The analysis was performed in two stages. First, evaluate the scales through Cronbach's alpha values, EFA and CFA. Second, the hierarchical regression method is used.

\section{Results And Discussions}

\section{A. Results}

\section{1) Describe the research sample}

The survey sample partly reflects the current situation of tourism human resources in Khanh Hoa province. Female employees are more than male (101 female, accounting for $58.38 \%$; 78 male/41.62\%). Including 9 people as leaders of departments $(5.20 \%), 25$ people as managers $(14.45 \%)$, and 139 employees $(80.35 \%)$. Most of them are experienced workers working for 3 to 8 years (128 employees/73.99\%), even more than 8 years $(10.40 \%)$. Only a few have less than 2 years of work experience (14.45\%).

\section{2) Reliabilities and Correlation coefficients}

In this step, twenty-eight questions are used to conduct exploratory factor analysis. Processing has removed seven items (of CSR scale) because the weight difference factor
$<$.3. Furthermore, removing these items does not change the content of the concepts. As a result, twenty-one questions were reduced into five components with a total variance explained of $70.28 \%(\mathrm{KMO}=.883$; Chi-square $=2065.084$; df $=2105 ; \mathrm{sig}=.000)$, load factor values from .60 to .86 . The CSR scale has only three components. Reliability and correlation between research concepts (Table 1): Employee work innovation, brand supporting behavior and CSR were shown as well as control variables including employee work experience, star rating of accommodation. The results of the correlation between the concepts support the hypothesis $\mathrm{H} 1$ and H2. Specifically, the correlation coefficients indicated a significant relationship between CSR and brand supporting behavior $(\mathrm{r}=.540, \mathrm{p}<.01)$ and the relationship between brand supporting behavior and employee work innovation $(\mathrm{r}=.449$, $\mathrm{p}<.01)$. Both coefficients were relevant with the hypotheses.

TABle 1:

Descriptive Statistics And Correlation Between Research Concepts

\begin{tabular}{ccccccccc}
\hline $\begin{array}{c}\text { No } \\
\cdot\end{array}$ & $\begin{array}{c}\text { Con- } \\
\text { cepts }\end{array}$ & Mean & S.D & $\mathbf{1}$ & $\mathbf{2}$ & $\mathbf{3}$ & $\mathbf{4}$ & $\mathbf{5}$ \\
\hline 1 & SR & 4.73 & .45 & & & & & \\
2 & WE & 10.49 & .50 & .132 & & & & \\
3 & CSR & 3.87 & .72 & -.079 & -.068 & .718 & & \\
4 & BSB & 4.02 & .67 & .010 & .029 & $.540^{* *}$ &. $\mathbf{8 5 8}$ & \\
5 & EWI & 3.84 & .62 & .127 & $.027^{* *}$ & $.338^{* * *}$ & $.449^{* *}$ & $\mathbf{. 8 5 1}$ \\
${ }^{* *} \mathrm{p}<.01 ;$ reliabilities appear on the diagonal. & & & \\
WE: employee work experience; SR: star rating of accommodation; \\
BSB: Brand supporting behavior; EWI: Employee work innovation.
\end{tabular}

\section{3) Evaluating the hypothesis}

For evaluating the hypothesis in the research model, the author used hierarchical linear modeling suggested by Bryk and Raudenbush [39]. The result of evaluation showed that CSR directly and positively affects brand supporting behavior (Table 2) and contributed significantly into explanation the change of dependent variables $(\mathrm{R} 2=.298, \Delta \mathrm{R} 2=.285)$.

\begin{tabular}{ccc} 
Table 2: Linear Regression For Brand Supporting Behavior \\
\hline Concepts & Model 1 & Model 2 \\
\hline WE & .028 & .060 \\
SR & .006 & .045 \\
CSR & & $.547^{* * *}$ \\
$\mathrm{R}^{2}$ & .001 & .298 \\
$\Delta \mathrm{R}^{2}$ & & .285 \\
\hline
\end{tabular}

Dependent variables: BSB; $* * *: \mathrm{p}<.001$.

WE: employee work experience; SR: star rating of accommodation; BSB: Brand supporting behavior; EWI: Employee work innovation.

For model 2 (Table 2), the regression results reflected that when the CSR (independent variable) was regressed to brand supporting behavior (intermediate variable) together with the controlled variables (Working time, hotel star), the regression coefficient was considered to be significant for the relationship between these two factors $\left(\beta=.547 ; \mathrm{p}<.001, \mathrm{R}^{2}\right.$ $\left.=.298, \Delta \mathrm{R}^{2}=.285\right)$. So hypothesis $\mathrm{H} 1$ was supported.

For hypothesis $\mathrm{H} 2$, the analysis results were presented in Model 2 (Table3).

The regression results of Model 2 (Table 3) reflected that when brand supporting behavior (mediating variable) was re- 


\begin{tabular}{ccc} 
Table 3: Linear Regression For Employee & Work Innovation \\
\hline Concepts & Model 1 & Model 2 \\
\hline WT & .193 & .181 \\
SR & .102 & .099 \\
BSB & & $.443^{* * * *}$ \\
$\mathrm{R}^{2}$ & .053 & .249 \\
$\Delta \mathrm{R}^{2}$ & & .235
\end{tabular}

Dependent variables: EWI; ***: $\mathrm{p}<.001$.

WE: employee work experience; SR: star rating of accommodation; BSB: Brand supporting behavior; EWI: Employee work innovation.

gressed on the employee work innovation (dependent variable), the regression coefficient was seem to be significant ( $\beta$ $\left.=.443 ; \mathrm{p}<.001, \mathrm{R}^{2}=.249 ; \Delta \mathrm{R}^{2}=.235\right)$. This result supported the second hypothesis (H2). The third hypothesis (H3) stated that brand supporting behavior plays a mediating role for the relationship between CSR and employee work innovation. Research used the mediation test of Baron and Kenny (1986) has required:

(i) The independent variables (CSR) were considered as premise variables for the intermediate variable (BSB) and predictor variables for the dependent variable (EWI).

(ii) The intermediate variable was the premise variable for the dependent variable.

(iii) The relationship between the independent variable and the dependent variable should decrease when the mediation variable is controlled.

The results of the regression analysis show that CSR was a significantly predicted factor to EWI, $\beta=.373$; $p<.001$ (see Model 2 - Table 4), also effected on BSB (corresponds to the hypothesis H1).

\begin{tabular}{|c|c|c|c|}
\hline Concepts & Model 1 & Model 2 & Model 3 \\
\hline WE & .193 & $.215^{* *}$ & $.194^{* * *}$ \\
\hline SR & .102 & .128 & .113 \\
\hline CSR & & $.373^{* * * *}$ & $.186^{* * *}$ \\
\hline BSB & & & $.342^{* * *}$ \\
\hline $\mathrm{R}^{2}$ & .053 & .191 & .273 \\
\hline$\Delta \mathrm{R}^{2}$ & & .176 & .255 \\
\hline
\end{tabular}

Dependent variables: EWI; ***: $\mathrm{p}<.001 ; * *: \mathrm{p}<.01$.

WE: employee work experience; SR: star rating of accommodation; BSB: Brand supporting behavior; EWI: Employee work innovation.

Next, the results (see Model 3 - Table 4) also showed that BSB positively affects EWI $(\beta=.342, p<.001)$. Finally, the results showed that the degree of influence of CSR on EWI has been significantly reduced, after the intermediate variable joined the test (with $\beta=.186$; $\mathrm{p}<.001$ ). This proves that employees who perceive their organization's CSR practices, act for the organization's brand, thereby employee work innovation will be increased too. So, hypothesis H3 was supported.

\section{B. Discussion}

This study is an attempt to examine the effects of CSR on brand supporting behavior and work innovation in Khanh
Hoa hospitality industry. Research has focused on individual psychological processes ranging from the perception of organizational responsible actions (towards the community, environment, employees, customers) to a positive psychological state, as reflected by employees' efforts in delivering on the organization's brand promise. That leads to employee work innovation. And so, CSR helps employees form positive behavior at work. This result supports the study of $\mathrm{Yu}$ and Choi [40].

With the analyzed data, the research results have shown the important role of CSR practices in the Vietnam hospitality industry, especially in the context of the Covid-19 pandemic. Specifically, through CSR activities, employees will gradually form positive attitudes and behaviors at work, promote personal development, and lead to innovative behavior. This finding supports previous studies, which showed the role of brand supporting behavior in positively affecting the brand in the hospitality industry [18].

With the results obtained, this study has helped to discover more about employee work innovation. The development of the hospitality industry goes hand in hand with the conservation of tourism resources. However, the limited availability of resources has also put great pressure on businesses. And employee work innovation helps the organization to make effective use of those resources. Therefore, employee work innovation plays a vital role in the business environment of the hotel industry.

Our study showed that brand supporting behavior seemed an vital mediating factor in increasing employee work innovation. Moreover, the result of analysis about mediating mechanisms has taken aware of the understanding of workers' positive motivation and development in increasing employee work innovation. Besides that, this study provided overview sight and evidence for supporting the point that brand supporting behavior is an vital self-regulation mechanism, which came from individual's mind, and helped them not only get the job done, but also deliver on the organizational brand promise.

Furthermore, this study has practical implications for managers. When employees perceive the actual activities of enterprises about CSR, they will put more effort in their work and act in accordance with the brand promise to customers. Thereby creating motivation for them to innovate at work. If workers have a positive motivation, they will gain more effort and work innovation will be increased. On the other hand, if organizations pay more attention to the employees' mental health, they will get more energy to learn knowledge, skills and employee work innovation will be increased, too. This is a reliable basis to help businesses build and choose appropriate strategies in each stage of development.

\section{Conclusion}

Innovation is an indispensable activity in the development strategy of every organization. Our study was conducted to explore the relationship between CSR, brand supporting behavior and employee work innovation. The results show the positive effects of CSR in developing a positive psychological state of employees, trying to fulfill the organizational 
brand promise. From there, it will stimulate discovery, creativity and innovation in their work.

Organizational behavior is a fairly large category, and so each study will have certain contributions. Our findings point to the important mediating role of brand supporting behavior in increasing employee work innovation. This discovery helps managers better understand the conditions affecting innovation, problem solving, stimulating creative ideas and innovative behavior of employees.

Moreover, the research results confirm the role of CSR practice not only as "the right thing to do" but also as "the smart thing to do" [41, p.60]. Thus, practicing CSR is considered a smart solution in the strategy of spreading the image and increasing the brand value of the organization, creating a competitive advantage, contributing to the sustainable development $[42,43]$. The efforts of the service staff to meet the diverse customer's needs create working pressure for them, leading to stress, exhaustion and rest [44]. Therefore, employees need to balance their workplace morale, in order to provide consumers with the best possible service. Participating in volunteer activities is one of the solutions to help them achieve that.

In conclusion, the study contributed to understanding better about the link between CSR, brand supporting behavior and employee work innovation, especially the employee who worked in the hospitality industry. Today, the workforce is not only concerned with job satisfaction, but also the work environment that can get them more positive motivation to learn and promote them better day by day. So on, this study proposed some suggestion:

- The study results explore the important regulatory mechanism of brand supporting behavior in the process of promoting innovation. Therefore, accommodations need to focus on managing human resources, particularly the function of training and developing human resources. From there, it is possible to create an environment that helps employees have a positive psychological state and strive to fulfill the organizational brand promise. Specifically, accommodations need to organize training activities and share experiences to help staff promote their strengths and confidently deal with all difficult situations.

- Besides brand supporting behavior, employee work innovation is also the result of CSR practices. Therefore, hotels and resorts need to focus on volunteering activities for the environment, community, customers and employees. More importantly, creating an organizational culture that shares employee knowledge and learning opportunities. Thereby improving the quality of relationships among members of the organization. It is the foundation to help employees work harder and thrive at work.

However, limitations of study still existed. Firstly, the research samples were collected from participants in the hospitality industry in Khanh Hoa province. Therefore, the findings of this study cannot give an overview for all. Secondly, we used a cross-sectional study method. It limited our ability to test causality or duality of relationships. Thirdly, the specific impact of each component in multi-pronged concepts has not been evaluated. Finally, the variety of concepts, and correlations in the study was still limited. These limitations will be the suggestions for further studies.

\section{REFERENCES}

[1] C. Prahalad and V. Ramaswamy, "Co-creating unique value with customers", Strategy and Leadership Strategy and Leadership, vol. 32, no. 3, pp. 4-9, 2004.

2] M. Vilanova, J.M. Lozano and D. Arenas, "Exploring the nature of the relationship between CSR and competitiveness", Journal of Business Ethics, vol. 87, pp. 57-69, 2009.

[3] K. Ayupp and T. Chung, "Empowerment: Hotel employees' perspective", Journal of Industrial Engineering and Management, vol. 3, no. 3, pp. 561-575, 2010.

[4] R. Stock and W. Hoyer, "An attitude behavior model of salespeople's customer orientation", Journal of the Academy of Marketing Science, vol. 33, no. 4, pp. 536-552, 2005.

[5] K. Punjaisri, H. Evanschitzky and A. Wilson, "Internal branding: an enabler of employees' brand-supporting behaviors", Journal of Service Management, vol. 20, no. 2, pp. 209-226, 2009.

[6] K. Punjaisri, A. Wilson and H. Evanschitzky, "Internal branding to influence employees' brand promise delivery: a case study in Thailand", Journal of Service Management, vol. 20, no. 5, pp. 561-579, 2009.

[7] F. M. Morhart, W. Herzog and T. Tomczak, "Brand-specific leadership: turning employees into brand champions", Journal of Marketing, vol. 73 , no. 5, pp. 122-142, 2009.

[8] A. Carmeli and G. Spreitzer, "Trust, connectivity, and thriving: Implications for innovative behaviors at work", The Journal of Creative Behavior, vol. 43, no. 3, pp. 169-191, 2009.

[9] O. Janssen, "Job demands, perceptions of effort-reward fairness and innovative work behaviour", Journal of Occupational and Organizational Psychology, vol. 73, no. 3, pp. 287-302, 2000.

[10] S. G. Scott and R.A. Bruce, "Determinants of innovative behaviour: a path model of individual innovation in the workplace", Academy of Management Journal, vol. 37, no. 3, pp. 580-607, 1994.

[11] F. Yuan and R. Woodman, "Innovative behavior in the workplace: The role of performance and image outcome expectations", Academy of Management Journal, vol. 53, no. 2, pp. 323-342, 2010.

[12] O. Janssen, E. Van de Vliert and M. West, "The bright and dark sides of individual and group innovation: A special issue introduction", Journal of Organizational Behavior, vol. 25, pp. 129-145, 2004

[13] M. West and N. Anderson, "Innovation in top management teams", Journal of Applied Psychology, vol. 81, no. 6, pp. 680-93, 1996.

[14] B. Machtiger, "Beware pitfalls that kill branding efforts", Marketing News, vol. 38, no, 4, pp. 21-22, 2004.

[15] C. Burmann and S. Zeplin, "Building brand commitment: A behavioral approach to internal brand management", Journal of Brand Management, vol. 12, no. 4, pp. 279-300, 2005.

[16] K. Punjaisri, A. Wilson and H. Evanschitzky, "Exploring the influences of internal branding on employees' brand promise delivery: Implications for strengthening the customer-brand relationships" Journal of Relationship Marketing, vol. 7, no. 4, pp. 407-424, 2008.

[17] C. King, "One size doesn't fit all: Tourism and hospitality employees' response to internal brand management", International Journal of Contemporary Hospitality Management, vol. 22, no. 4, pp. 517-534, 2010.

[18] C. Burmann, S. Zeplin and N. Riley, "Key determinants of internal brand management success: an exploratory empirical analysis", Journal of Brand Management, vol. 16, no. 4, pp. 264-284, 2009.

[19] T.L. Baker, A. Rapp, T. Meyer and R. Mullins, "The role of brand communications on front line service employee beliefs, behaviors, and performance", Journal of Academy of Marketing Science, vol. 42, pp. 642-657, 2014

[20] K. Thomson, L. deChernatony, L. Arganbright and S. Khan, "The buyin benchmark: How staff understanding and commitment impact brand and business performance", Journal of Marketing Management, vol. 15 , pp. 819-835, 1999.

[21] J.L. Holcomb, R.S. Upchurch and F. Okumus, "Corporate Social Responsibility: What are the top hotel companies reporting? ", International Journal of Contemporary Hospitality Management, vol. 19, no. 6, pp. 461-475, 2007.

[22] Y. Inoue and S. Lee, "Effects of different dimensions of corporate social responsibility on corporate financial performance in tourismrelated industries", Tourism Management, vol. 32, pp. 790-804, 2011.

[23] ISO 26000:2010, link: http://www.iso.org

[24] M. Santhosh and R. Baral, "A Conceptual Framework for Exploring the Impacts of Corporate Social Responsibility on Employee Attitudes and Behaviour", Journal of Human Values, vol. 21, no. 2, pp. 127-136, 2015.

[25] C. Bartel, "Social comparisons in boundary-spanning work: effects of community outreach on members' organizational identity and 
identification", Administrative Science Quarterly, vol. 46, no. 3, pp 379-413, 2001.

[26] H. L. Kim, Y. Rhou, M. Uysal and N. Kwon, "An examination of the links between corporate social responsibility (CSR) and its internal consequences", International Journal of Hospitality Management, vol. 61, pp. 26-34, 2017.

[27] R. Cropanzano, Z.S. Byrne, D.R. Bobocel and D.E. Rupp, "Moral virtues, fairness heuristics, social entities, and other denizens of organizational justice", Journal of Vocational Behavior, vol. 58, pp. 164-209, 2001.

[28] V. Cherapanukorn and K. Focken, "Corporate Social Responsibility (CSR) and Sustainability in Asian Luxury Hotels: Policies, Practices and Standards", Asian Social Science, vol. 10, no. 8, pp. 198-209, 2014

[29] M.T. Azim, "Corporate Social Responsibility and employee behavior mediating role of organizational commitment", Review of Business Management, vol. 18, no. 60, pp. 207-225, 2016.

[30] K. O. Park, "How CSV and CSR Affect Organizational Performance: A Productive Behavior Perspective", International Journal of Environmental Research and Public Health, vol. 17, pp.2556, 2020.

[31] G. Oldham and J. Hackman, "Not what it was and not what it will: The future of job design research", Journal of Organizational Behavior, vol. 31, pp. 463-479, 2010.

[32] K. T. Blau, "LMX-citizenship behavior relationship: justice as a mediator", Leadership \& Organization Development Journal, vol. 27, no. 2, p. 106-117, 2006.

[33] S. E Levy and S.Y. Park, "An analysis of CSR activities in the lodging industry", Journal of Hospitality and Tourism management, vol. 18, pp. 147-154, 2011.

[34] P. Martınez, A. Perez and I.R. Bosque, "CSR influence on hotel brand image and loyalty", Academia Revista Latinoamericana de Administration, vol. 27, no. 2, pp. 267-283, 2014.

[35] S. Y. Park and S. E. Levy, "Corporate social responsibility: perspectives of hotel frontline employees", International Journal of
Contemporary Hospitality Management, vol. 26, no. 3, pp. 332-348, 2014

[36] M. Fatma, Z. Rahman and I. Khan, "Multi-item stakeholder based scale to measure CSR in the banking industry", International Strategic Management Review, vol. 2, no. 1, pp. 9-20, 2014

[37] D. Turker, "Measuring Corporate Social Responsibility: A Scale Development Study Duygu Turker", Journal of Business Ethics, vol. 85, pp. 411-427, 2009.

[38] C.A. Benavides-Velasco, C. Quintana-García and M. Marchante-Lara, "Total quality management, corporate social responsibility and performance in the hotel industry", International Journal of Hospitality Management, vol. 41, pp. 77-87, 2014.

[39] A. S. Bryk and S.W. Raudenbush, "Hierarchical linear models: Applications and data analysis. Methods", Newbury Park, CA: Sage, 1992.

[39] H. R. Kim, M. Lee, H. T. Lee and N. M. Kim, "Corporate social responsibility and employee-Company Identification", Journal of Business Ethics, vol. 95, no. 4, pp. 557-569, 2010.

[40] Y. Yu and Y. Choi, "Corporate social responsibility and firm performance through the mediating effect of organizational trust in Chinese firms", Chinese Management Studies, vol. 8, no. 4, pp. 577$592,2014$.

[41] N. C. Smith, "Corporate social responsibility: whether or how?", California Management Review, vol. 45, no. 4, pp. 52-76, 2003.

[42] P. S. Bronn and A.B. Vrioni, "Corporate social responsibility and cause-related marketing: an overview", International Journal of Advertising, vol. 20, pp. 207-222, 2001.

[43] J. M. S Filho, L.S.O. Wanderley, C.P. Golmez and F. Farache, "Strategic corporate social responsibility management for competitive advantage", Brazilian Administration Review, vol. 7, no. 3, pp. 294309, 2010.

[44] D. V. Pavesic and R. A. Brymer, "Job satisfaction: what's happening to the young manager?", Cornell Hotel and Restaurant Administration Quarterly, vol. 30, no. 4, pp. 90-96, 1990. 